\title{
Controversies in using urine samples for Prostate Cancer detection: PSA and PCA3 expression analysis
}

\author{
S. Fontenete, J. Silva, A.L. Teixeira, R. Ribeiro, E. Bastos, F. Pina, R. Medeiros \\ Molecular Oncology Group and Virology LB (SF, JS, ALT, RR, RM), Portuguese Institute of Oncol- \\ ogy of Porto; ICBAS, Abel Salazar Institute for the Biomedical Sciences (SF, JS, ALT, RR, RM), \\ University of Porto; Research Department - Portuguese League Against Cancer (NRN) (JS, ALT, \\ RR, RM), Porto; Centre of Genetics and Biotechnology (EB), University of Trás-os-Montes and Alto \\ Douro; Department of Urology (FP), S. João Hospital, University of Porto Medical School; CE- \\ BIMED, Faculty of Health Sciences of Fernando Pessoa University (RM), Porto, Portugal
}

\begin{abstract}
Purpose: Prostate cancer (PCa) is one of the most commonly diagnosed malignancies in the world. Although PSA utilization as a serum marker has improved prostate cancer detection it still presents some limitations, mainly regarding its specificity. The expression of this marker, along with the detection of PCA3 mRNA in urine samples, has been suggested as a new approach for PCa detection. The goal of this work was to evaluate the efficacy of the urinary detection of PCA3 mRNA and PSA mRNA without performing the somewhat embarrassing prostate massage. It was also intended to optimize and implement a methodological protocol for this kind of sampling.

Materials and Methods: Urine samples from 57 patients with suspected prostate disease were collected, without undergoing prostate massage. Increased serum PSA levels were confirmed by medical records review. RNA was extracted by different methods and a preamplification step was included in order to improve gene detection by Real-Time PCR.

Results: An increase in RNA concentration with the use of TriPure Isolation Reagent. Despite this optimization, only $15.8 \%$ of the cases showed expression of PSA mRNA and only $3.8 \%$ of prostate cancer patients presented detectable levels of PCA3 mRNA. The use of a preamplification step revealed no improvement in the results obtained.

Conclusion: This work confirms that prostate massage is important before urine collection for gene expression analysis. Since PSA and PCA3 are prostate specific, it is necessary to promote the passage of cells from prostate to urinary tract, in order to detect these genetic markers in urine samples.
\end{abstract}

Key words: Prostatic Neoplasms; Biomarkers; Urine; prostate-specific antigen

Int Braz J Urol. 2011; 37: 719-726

\section{INTRODUCTION}

Prostate cancer $(\mathrm{PCa})$ is one of the most commonly diagnosed malignancies in the developed world (1). Since this disease is more common among older men, its incidence is expected to increase as the population ages. Application of emerging genomic technologies to high-quality PCa models and patient samples, in multiple contexts, has made significant contributions to our molecular understanding of the development and progression of this disease (2).
An ideal marker for the early detection of PCa should also be able to differentiate between men with isolated high grade prostatic intraepithelial neoplasia (HGPIN) and those with associated PCa (2). Prostate-specific antigen (PSA) measurement, obtained from a simple blood sample, has been widely proposed as a screening tool for $\mathrm{PCa}$, being currently the leading cancer diagnosis in men in several developing countries (2). PSA is prostate-specific but not cancer-specific, since other benign prostate diseases often cause its increase in serum. On the other 
hand, most men with high levels of PSA do not have $\mathrm{PCa}$ (3). Due to this lack of specificity, many studies have proposed modifications of PSA measurement in an attempt to improve the performance of this analysis. These modifications include PSA density, age-specific PSA ranges, free to total PSA ratios, complexed PSA, transition zone PSA density, PSA velocity and other PSA isoforms such as proPSA (4). Despite these changes, there are still inherent limitations to PSA use as a screening tool for PCa. This highlights the need to complement this test, by using for example high performance biomarkers capable of distinguish, with greater specificity, cancer from non-cancer patients. At the same time, this approach will identify men with aggressive cancer with highly precision, thereby reducing unnecessary biopsies.

The development of biomarkers for $\mathrm{PCa}$ screening, detection and prognostication has revolutionized the management of this disease (5). Nowadays, there are many clinical studies which evaluate biomarkers in urine (1). This type of sample represents a good fluid to seek biomarkers, mainly because it is readily available and obtained noninvasively. On the other hand, it can be used to detect either exfoliated cancer cells or secreted prostatic products that could indicate the presence of PCa (1). Prostate cells are believed to be present in urine, especially in the first voided sample after prostate massage.

The prostate cancer antigen 3 (PCA3) gene was identified because of its differential expression between prostate cancer and noncancerous prostate tissue (normal gland or benign hypertrophy) (6). Its RNA is regarded as a member of the non-coding RNA family and is thought to participate in the regulation of gene expression at various levels (7). Reverse transcriptase (RT)-PCR on urine sediments obtained after prostatic massage showed a sensitivity and specificity of PCA3 detection of $66 \%$ and $89 \%$, respectively (8). Analysis of changes in the expression levels of large numbers of genes during PCa progression have provided a better understanding of the basis of the disease, yielding new molecular markers with potential use in diagnosis and prognosis of this disease, when combined with PSA and PCA3 (9).

This work represents a pilot study, with the intention to evaluate the efficacy of PCA3 mRNA and PSA mRNA detection in urine samples without performing the somewhat embarrassing prostate massage, as well as to optimize and implement a methodological protocol for this kind of sample.

\section{MATERIALS AND METHODS}

From February 2009 to January 2010, whole urine specimens were collected from 57 men before ultrasound-guided prostate biopsy according to a protocol approved by the Hospital of São João, Porto. Patient characteristics and diagnostic information are listed in Table-1. All men who presented for prostate biopsy were approached about participating in this study. Inclusion criteria included adult men who were undergoing prostate biopsy for suspicion of prostatic disease. Before prostate biopsy and without performing a prostatic massage, patients collected their initial void of $20 \mathrm{~mL}$ to $30 \mathrm{~mL}$ of urine, and the sample was then processed at the Portuguese Institute of Oncology, Porto. The samples were subsequently stabilized a TriPure ${ }^{\circledR}$ Isolation Reagent (Roche Applied Science, Cat $\mathrm{N}^{\mathrm{o}} 11$ 667165001 ) and kept at $-80^{\circ} \mathrm{C}$. There were added $2 \mu \mathrm{L}$ of glycogen to the urinary sediment, as a carrier (Roche Applied Science, Cat No 10901393 001). Total RNA was extracted from these urinary sediments, using TriPure ${ }^{\circledR}$ protocol adapted from Keck Foundation Biotechnology Resource Laboratory at Yale Microarray University. RNA $(100 \mu \mathrm{g} / \mu \mathrm{L})$ was used as a template for cDNA synthesis, using cDNA synthesis kit ThermoScript ${ }^{\mathrm{TM}} \mathrm{RT}$-PCR System (Invitrogen, Cat $\left.n^{\circ} 11146-016\right)$, and stored at $-40^{\circ} \mathrm{C}$ until quantitative PCR analysis. To develop a qPCR-based test for $\mathrm{PCa}$, we assessed two putative biomarkers in 57 patients. The genes under analysis and the endogenous control GAPDH, all from TaqMan ${ }^{\circledR}$ Gene Expression Assay (Applied Biossystems), had to be analyzed by quantitative real time PCR (qPCR) (Table-2). We also applied two preamplification techniques, using the commercial kit TaqMan ${ }^{\circledR}$ PreAmp Master Mix Kit (Applied Biosystems, PN 4384267), in order to verify if this would affect the detection of RNA transcripts. This step was performed according to the manufacturer's instructions. Reactions were then carried out on a StepOne ${ }^{\mathrm{TM}}$ One qPCR machine and the threshold levels were set into the exponen- 
Table 1 - Patient characteristics.

\begin{tabular}{lccc}
\hline & Prostate Ca & Nonprostate Ca & p value \\
\hline No. pts & 25 & 32 & \\
Mean \pm SD age & $69.16 \pm 7.40$ & $65.19 \pm 7.38$ & 0.051 \\
Mean \pm SD PSA level, ng/mL & $24.95 \pm 56.78$ & $7.92 \pm 6.13$ & 0.097 \\
No. Gleason score (\%) & & & \\
$5-6$ & $5(20)$ & - & \\
$7-8$ & $18(72)$ & - & \\
\hline
\end{tabular}

Table 2 - Gene characteristic and TaqMan ${ }^{\circledR}$ GeneExpression Assay (Applied Biossystems).

\begin{tabular}{lccc}
\hline Gene & Official Full Name & Chromosome location & Assay ID \\
\hline PCA3 & Prostate cancer antigen 3 (non-protein coding) & $9 \mathrm{q} 21-\mathrm{q} 22$ & Hs01371938_m1 \\
PSA & Prostate specific antigen & $19 \mathrm{q} 13.41$ & Hs02576345_m1 \\
GAPDH & Glyceraldehyde-3-phosphate dehydrogenase & $12 \mathrm{p} 13$ & Hs99999905_m1 \\
\hline
\end{tabular}

tial phase of the qPCR. Glyceraldehyde 3-phosphate dehydrogenase $(G A P D H)$ was used to normalize the results, since it presents a constant expression level, regardless of the variables in study. The data analysis was carried out using the StepOne Software $v 2.1$ (Applied Biossystems) with the same baseline and threshold set for each plate, in order to generate threshold cycle $\left(C_{t}\right)$ values for all the genes in each sample.

\section{RESULTS}

qPCR was performance on cDNA from urine collected from 32 biopsy-negative patients and 25 patient with prostate cancer (biopsy-positive). All the samples had gene $C_{t}$ values of $>30$. It was observed an increase in RNA concentration with the use of TriPure Isolation Reagent. Despite this optimization, only $15.8 \%$ of the cases showed expression of PSA mRNA $(16 \%$ within PCa cases and $15.6 \%$ in benign cases) and only $3.8 \%$ of prostate cancer patients presented detectable levels of PCA3 mRNA.

Our results demonstrated that TaqMan ${ }^{\circledR}$ PreAmp doesn't overcome the difficulties usually caused by low yields of RNA extraction.
PSA serum levels and PSA mRNA were first tested by univariate analysis, showing no significant association for discrimination patients with prostate cancer from patients with non-oncological disease ( $p$ $=0.097$ and 0.058 (Figure-1), respectively).

\section{DISCUSSION}

PSA is currently the gold standard for PCa screening (3). However, there have been a few drawbacks in its use, mainly regarding sensitivity and specificity values, leading to an overdiagnosis. It is therefore fundamental to diminish the number of unnecessary biopsies in men without cancer. Furthermore, it is crucial to improve tumor detection in men who presents normal values of PSA. This could be achieved by discovering other biomarkers that can be useful in the diagnosis of $\mathrm{PCa}$, avoiding its progression to metastatic disease (5).

Molecular biomarkers are capable of detecting tumors in early phases before these could be identified by other approaches. The use of such markers can also help us understand the causes and mechanisms involved in tumor development (10). All of this highlights the importance of biomarker 
Figure 1-Box plot of prostate-specific antigen (PSA) normalized expression.

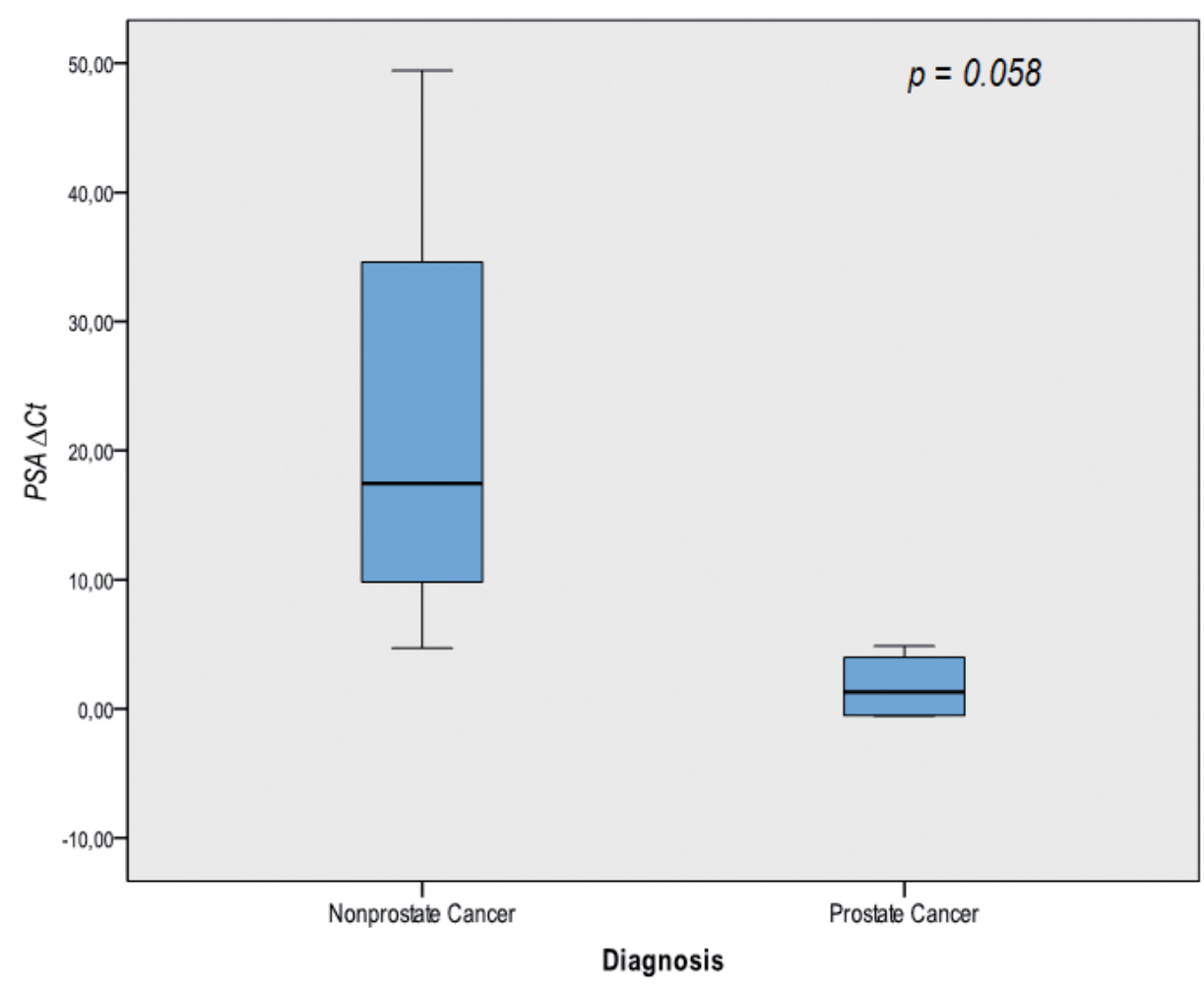

studies, in order to discover new screening techniques for PCa. However, the establishment of these biomarkers represents a challenge, mainly on methodological and analytic levels. It is therefore necessary to optimize its use, so that the results obtained are valid.

We employed a novel TaqMan ${ }^{\circledR}$ PreAmp technique which we found to be a practical solution to decrease $\mathrm{Ct}$ values, and in particular suitable in our hands to generate real time PCR results from limited amounts of input RNA (11). The results obtained using TaqMan ${ }^{\circledR}$ real time PCR, with or without PreAmp procedure were not enough to be analyzed, since there where only a few cases where the detection was possible (only $15.8 \%$ of the cases showed expression of PSA mRNA and only $3.8 \%$ of prostate cancer patients presented detectable levels of PCA3 mRNA). Previous studies have also revealed some difficulties in urinary mRNA detection $(12,13)$. This may be caused by various factors, being one of the most emerging the type of sample used. In the case of urine samples, they require tumor cells exfoliation, which can be obtained by application of prostate massage before sample collection (9). However, this is an invasive approach that goes against some of the advantages of urinary samples, as its easy collection.

When we analyze the results for PSA mRNA detection, we verified only a few positive cases. Since this gene is prostate specific, it would be expected that all samples showed some level of expression. These results may be due to the lack of prostate massage before urine collection (14). The biomarkers concentration in the samples might therefore be low, not allowing its detection. Despite the invasiveness associated with prostate massage, it is important to evaluate whether this procedure presents more advantages to the patient when compared, for instance, with biopsy.

Interestingly, it was found some differences in PSA mRNA expression levels between the two groups analyzed $(p=0.058)$. Men diagnosed with $\mathrm{PCa}$ appear to express higher levels of PSA mRNA, 
when compared to men without oncologic disease. However, when we accessed PSA serum levels by medical records review, we found no statistical differences between the two groups $(p=0.097)$. Previous studies have proposed the existence of some factors which may affect PSA serum levels such as the initiation of stating treatment and NSAID consumption $(15,16)$. On the other hand, it was also suggested that some prostate manipulation, namely DRE and prostate biopsy, may also affect serum PSA levels $(17,18)$. Nonetheless, a previous study led by Croccito et al. revealed low values of sensitivity and specificity for biomarker detection, regardless of prostate massage application (19). This highlights the existence of other variables that should be optimized, in order to create a universal protocol capable of providing feasible results.

The company Gen-Probe Inc. has developed a technology based on transcription-mediated amplification (TMA) (20) for mRNA detection in urine samples. However, it presents some disadvantages, including the cost per sample and the need for repetition and forprostate massage. Comparative analysis of the results obtained in several studies using RTPCR or TMA show that the levels of detection in terms of sensibility and specificity are similar (Table-3) (20-25).

Another issue to be concerned regards the variability showed by urinary samples, namely its volume, protein concentration and $\mathrm{pH}$ value. An additional problem that has to be considered is related to the use of first morning urine. Despite its advan- tage in leading to a greater likelihood of prostate cells detection, this kind of sample may also incite to further degradation of RNA, since it contains a higher concentration of proteins. Thus, the use of urine samples analyzed on the "spot of collection" prevents this increase in RNA degradation. However, on the other hand, this kind of sample makes it difficult to detect specific cells of the prostate.

It is also necessary to be aware of the variability that exists in urine samples not only among cases but also in the same individual. In addition, it is crucial to provide good storage for the samples so their degradation can be prevented (26). Previous studies on PSA mRNA detection in blood revealed conflicting results, which suggests the existence of others variables that should be controlled, like the kind of biomarker in study. The use of RNA presents a few drawbacks, mainly regarding degradation and isolation. Studies using this molecule become therefore more difficult when it is not possible to process the samples right after its collection (27).

The cDNA synthesis is another step that should also be optimized, since it could affect the reaction efficiency by making it more difficult to detect RNA transcripts. Many reagents such as guanidine, reverse transcriptase, and dithiothreitol have a deleterious effect on downstream enzymatic reactions (28). The secondary structures and the complexity of proteins present in samples of RNA can interfere with the enzymatic reaction, leading to the arrest of the enzyme or its dissociation from the chains of cDNA or heel regions (29).

Table 3 - Several studies in urine based PCA3.

\begin{tabular}{lcccc}
\hline Study & Methodology & $\begin{array}{c}\text { Patients } \\
\text { number }\end{array}$ & $\begin{array}{c}\text { Sensitivity } \\
\text { (\%) }\end{array}$ & $\begin{array}{c}\text { Specificity } \\
\text { (\%) }\end{array}$ \\
\hline Hessels et al., 2003 (21) & RT-PCR fluorescent based & 108 & 67 & 83 \\
van Gils et al., 2007 (20) & RT-PCR fluorescent based & 534 & 65 & 66 \\
Groskopf et al., 2006 (22) & TMA & 70 & 69 & 79 \\
Marks et al., 2007 (23) & TMA & 233 & 58 & 72 \\
Deras et al., 2008 (24) & TMA & 570 & 54 & 74 \\
Hessels et al., 2009 (25) & TMA & 470 & 47 & 72 \\
\hline
\end{tabular}


The population chosen for the study could also affect the results, so its selection is extremely important. Attending the slow progression of $\mathrm{PCa}$, it is expected that some genes and pathways may involved only in some stages of the disease. Therefore, the inclusion of men with only localized disease, for example, may influence any results regarding the expression of selected genes. This is due to the fact that highly differentiated tumors tend to present less cell exfoliation in urine, when compared with more advanced tumors. This results in a more difficult detection of biomarkers in patients who present more initial stages of the disease, which does not necessarily mean that the genes in study do not have a role in tumor development. The results can therefore be deceiving, since these genes can be involved in later stages of the disease. Nevertheless, they can be very useful in prognosis.

\section{CONCLUSIONS}

According to the results obtained in the present study we may hypothesised that PSA mRNA is not affected by the same factors which influence PSA serum concentration, making the first a better option for PCa diagnosis, since it presents a higher efficacy.

One approach that should be explored is the use of positive markers along with negative markers, i.e. markers which expression increases and diminishes, respectively, in tumor tissues. This is expected to improve tumor detection specificity, thereby improving PCa screening. However, the use of several markers can also adversely affect the test's sensitivity and specificity for cancer detection, so test selection is crucial. The use of multiple biomarkers with high sensitivity, high specificity, and that are complementary may approach the optimal detection model.

The use of urinary biomarkers is still in an early stage, so more studies are necessary. The results of this work highlight the importance of a universal protocol for sample collection and process. This will decrease the variability of the results obtained, making the approach clinically valid. It is also important that such protocol can be applied to screening tests, which implies the selection of stable and resistant biomarkers, so that may be possible to send the urine samples from population to adequate labs, without its degradation.

This study reinforces the need to perform prostate massage before urine collection, as suggested before. However, there are other variables that should be taken into account, namely the challenging manipulation of RNA and the importance of implementing a universal protocol. Despite all limitations, the use of urinary biomarkers represents a major change in oncologic investigation, providing new insights to tumor developing.

\section{ACKNOWLEDGMENTS:}

This work was realized with the support from Calouste Gulbenkian Foundation (Oncology/2008/ Project $n^{\circ}$ 96736). We also acknowledge the support from FCT- Science and Technology Foundation (FCT/PTDC/SAU-FCF/71552/2006) ALT and RR are recipients of a Doctoral degree grant from FCT (SFRH/BD/47381/2008, SFRH/BD/30021/2006, respectively).

\section{CONFLICT OF INTEREST}

None declared.

\section{REFERENCES}

1. Downes MR, Byrne JC, Pennington SR, Dunn MJ, Fitzpatrick JM, Watson RW: Urinary markers for prostate cancer. BJU Int. 2007; 99: 263-8.

2. Morote J, Fernández S, Alaña L, Iglesias C, Planas $\mathrm{J}$, Reventós J, et al.: PTOV1 expression predicts prostate cancer in men with isolated high-grade prostatic intraepithelial neoplasia in needle biopsy. Clin Cancer Res. 2008; 14: 2617-22.

3. Loeb S, Catalona WJ: What to do with an abnormal PSA test. Oncologist. 2008; 13: 299-305.

4. Lin DW: Beyond PSA: utility of novel tumor markers in the setting of elevated PSA. Urol Oncol. 2009; 27: 315-21.

5. Schiffer E: Biomarkers for prostate cancer. World $\mathrm{J}$ Urol. 2007; 25: 557-62. 
6. Bussemakers MJ, van Bokhoven A, Verhaegh GW, Smit FP, Karthaus HF, Schalken JA, et al.: DD3: a new prostate-specific gene, highly overexpressed in prostate cancer. Cancer Res. 1999; 59: 5975-9.

7. Mattick JS, Makunin IV: Non-coding RNA. Hum Mol Genet. 2006; 15(Spec No 1): R17-29.

8. Fradet Y, Saad F, Aprikian A, Dessureault J, Elhilali M, Trudel C, et al.: uPM3, a new molecular urine test for the detection of prostate cancer. Urology. 2004; 64: 311-5; discussion 315-6.

9. Laxman B, Morris DS, Yu J, Siddiqui J, Cao J, Mehra R, et al.: A first-generation multiplex biomarker analysis of urine for the early detection of prostate cancer. Cancer Res. 2008; 68: 645-9.

10. Steuber T, Helo P, Lilja H: Circulating biomarkers for prostate cancer. World J Urol. 2007; 25: 111-9.

11. Gibson UE, Heid CA, Williams PM: A novel method for real time quantitative RT-PCR. Genome Res. 1996; 6: 995-1001.

12. Jerónimo $C$, Usadel $H$, Henrique $R$, Silva $C$, Oliveira J, Lopes C, et al.: Quantitative GSTP1 hypermethylation in bodily fluids of patients with prostate cancer. Urology. 2002; 60: 1131-5.

13. Gonzalgo ML, Isaacs WB: Molecular pathways to prostate cancer. J Urol. 2003; 170: 2444-52.

14. Papatsoris A, Bourdoumis A, Chrisofos MÇ Re: Accuracy of PCA3 Measurement in Predicting Short-Term Biopsy Progression in an Active Surveillance Program J. J. Tosoian, S. Loeb, A. Kettermann, P. Landis, D. J. Elliot, J. I. Epstein, A. W. Partin, H. B. Carter and L. J. Sokoll J Urol 2010; 183: 534-538. J Urol. 2010; 184: 396-7.

15. Hamilton RJ, Goldberg KC, Platz EA, Freedland SJ: The influence of statin medications on prostatespecific antigen levels. J Natl Cancer Inst. 2008; 100: 1511-8.

16. Singer EA, Palapattu GS, van Wijngaarden E: Prostate-specific antigen levels in relation to consumption of nonsteroidal anti-inflammatory drugs and acetaminophen: results from the 2001-2002 National Health and Nutrition Examination Survey. Cancer. 2008; 113: 2053-7.

17. Collins GN, Martin PJ, Wynn-Davies A, Brooman PJ, O'Reilly PH: The effect of digital rectal examination, flexible cystoscopy and prostatic biopsy on free and total prostate specific antigen, and the free-to-total prostate specific antigen ratio in clinical practice. J Urol. 1997; 157: 1744-7.
18. Lin YH, Jiang YG, Li MC, Luo Y, Wang JS: Effects of prostate manipulation on serum total and free prostate specific antigen, and free-to-total prostate specific antigen ratio. Saudi Med J. 2010; 31: 9991004.

19. Crocitto LE, Korns D, Kretzner L, Shevchuk T, Blair SL, Wilson TG, et al.: Prostate cancer molecular markers GSTP1 and hTERT in expressed prostatic secretions as predictors of biopsy results. Urology. 2004; 64: 821-5.

20. van Gils MP, Hessels D, van Hooij O, Jannink SA, Peelen WP, Hanssen SL, et al.: The time-resolved fluorescence-based PCA3 test on urinary sediments after digital rectal examination; a Dutch multicenter validation of the diagnostic performance. Clin Cancer Res. 2007; 13: 939-43.

21. Hessels D, Klein Gunnewiek JM, van Oort I, Karthaus HF, van Leenders GJ, van Balken B, et al.: DD3(PCA3)-based molecular urine analysis for the diagnosis of prostate cancer. Eur Urol. 2003; 44: 8-15; discussion 15-6.

22. Groskopf J, Aubin SM, Deras IL, Blase A, Bodrug $\mathrm{S}$, Clark C, et al.: APTIMA PCA3 molecular urine test: development of a method to aid in the diagnosis of prostate cancer. Clin Chem. 2006; 52: 108995.

23. Marks LS, Fradet Y, Deras IL, Blase A, Mathis J, Aubin SM, et al.: PCA3 molecular urine assay for prostate cancer in men undergoing repeat biopsy. Urology. 2007; 69: 532-5.

24. Deras IL, Aubin SM, Blase A, Day JR, Koo S, Partin AW, et al.: PCA3: a molecular urine assay for predicting prostate biopsy outcome. J Urol. 2008; 179: 1587-92.

25. Hessels D, Schalken JA: The use of PCA3 in the diagnosis of prostate cancer. Nat Rev Urol. 2009; 6: 255-61.

26. Thomas CE, Sexton W, Benson K, Sutphen R, Koomen J: Urine collection and processing for protein biomarker discovery and quantification. Cancer Epidemiol Biomarkers Prev. 2010; 19: 953-9.

27. Medeiros M, Sharma VK, Ding R, Yamaji K, Li B, Muthukumar T, et al.: Optimization of RNA yield, purity and mRNA copy number by treatment of urine cell pellets with RNAlater. J Immunol Methods. 2003; 279: 135-42. 
28. Tichopad A, Didier A, Pfaffl MW: Inhibition of real-time RT-PCR quantification due to tissue-specific contaminants. Mol Cell Probes. 2004; 18: 45-50.

Submitted for publication:

November 24, 2010

29. Liss B: Improved quantitative real-time RT-PCR for expression profiling of individual cells. Nucleic Acids Res. 2002; 30: e89.

\footnotetext{
Correspondence address:

Dr. Rui Medeiros

Molecular Oncology Group Coordinator

Portuguese Institute Of Oncology

Associate Professor, Icbas

Instituto Ciências Biomédicas

Abel Salazar (University Of Porto)

Largo Prof. Abel Salazar, 2

Porto, 4099-003, Portugal

Telephone: + 35122 2062-200

E-mail: ruimedei@ipoporto.min-saude.pt
}

Accepted after revision:

June 01, 2011 